\title{
TEATRO DE BONECOS: TRANSFORMAÇÕES NA POÉTICA DA LINGUAGEM ${ }^{1}$
}

\author{
Valmor Beltrame², Kátia de Arruda ${ }^{3}$
}

Palavras-chave: Linguagem Teatral, Teatro de Animação, Heterogeneidade da Linguagem

Resumo: O objetivo desta pesquisa foi abordar as principais características do Teatro de Animação contemporâneo catarinense e as principais transformações sofridas por esta linguagem neste estado. A idéia da pesquisa surgiu através da constatação de que esta é uma arte bastante viva e fecunda nesta região, não somente pelo grande número de artistas e grupos que atuam profissionalmente, como também pela qualidade e quantidade dos espetáculos que são produzidos.

O trabalho de investigação realizou-se através de entrevistas e da aplicação de questionários, com este procedimento pretendeu-se resgatar a trajetória profissional destes artistas, para que através da identificação de acontecimentos e situação vividas por eles, pudessem ser levantados fatos relevantes na história do teatro de animação catarinense, que apontassem na direção das principais mudanças ocorridas nesta linguagem teatral. Também foram examinados documentos escritos, como críticas publicadas em jornais e na internet, e programas de espetáculos e de festivais especializados na linguagem do Teatro de Animação no estado.

Atualmente, Santa Catarina conta com três festivais que apresentam exclusivamente espetáculos com esta linguagem artística, o Festival de Formas Animadas de Jaraguá do Sul, festival que ocorre anualmente e este ano entra em sua sétima edição, o Festival Catarinense de Teatro de Bonecos, que acontece bianualmente na cidade de Rio do Sul e entra na sua quarta edição, e o recéminaugurado FITA - Festival Internacional de Teatro de Animação que aconteceu este ano, na cidade de Florianópolis. Além disso, acontece anualmente o Festival Nacional de Teatro Infantil de Blumenau, que este ano entra em sua décima primeira edição e que sempre tem trazido em sua programação um número significativo de espetáculos que utilizam a Linguagem do Teatro de Animação. A cidade de Rio do Sul também sedia o Centro de Pesquisa e Produção de Teatro de Bonecos - Anima Bonecos, Ponto de Cultura do Governo Federal que tem a frente de seus trabalhos o atoranimador William Sieverdt e o construtor e ator-animador Paulo Nazareno Bernardo.

Atualmente existem 10 grupos de maior visibilidade que trabalham com a linguagem do Teatro de Animação em Santa Catarina: Cia. Mútua, de Balneário Camboriú; Cirquinho do Revirado, de Cruciúma; Experimentus, de Itajaí; GATS, de Jaraguá do Sul; Jabuti, de Florianópolis; Legião de Palhaços, de Florianópolis; Nazareno Bonecos, de Rio do Sul; Teatro Sim...Porque Não?, de Florianópolis; Téspis, de Florianópolis e Turma do Papum, também de Florianópolis. Dois atoresanimadores que atuam como solistas: Sérgio Murilo Bessa, de Florianópolis e William Sieverdt de Rio do Sul.

\footnotetext{
1 Projeto de Pesquisa CEART/UDESC

2 Orientador, Professor do Departamento de Artes Cênicas - Centro de Artes - Av. Madre Benvenuta, 1907 - Itacorubi - CEP 88035-001 - Florianópolis - SC.

3 Acadêmica do Curso de Artes Cênicas - CEART/UDESC, bolsista de iniciação científica do $\mathrm{PIBIC/CNPq}$.
} 
Por Teatro de Animação ${ }^{4}$ designamos as formas de teatro que utilizam e integram máscaras, bonecos, sombras, objetos e o corpo do ator. As principais características do Teatro de Animação são: a passagem do inaninado ao animado, e a mediação da relação entre ator-animador ${ }^{5}$ e público pela presença de um objeto. Segundo Beltrame ${ }^{6}$ :

O uso de variados meios de expressão, o abandono do boneco do tipo antropomorfo, a ruptura com o palquinho do tradicional teatro de bonecos e a presença visível do ator-animador na cena, tornam o teatro de animação produzido atualmente, um teatro bastante heterogêneo. Sua proximidade com outras linguagens artísticas incluindo a dança, mímica, circo, teatro de atores e espetáculo multimídia, entre outros, tornam esta arte reconhecidamente mais contemporânea, porém heterogênea, distanciada dos códigos e registros que historicamente a tornaram conhecida do grande público.

(BELTRAME, 2002:3)

Jurkowsky $^{7}$ utiliza a expressão teatro de bonecos homogêneo para designar um teatro de bonecos tradicional, ainda não contaminado por outros meios de expressão. É um teatro já adaptado às exigências da arte teatral, que tem por características principais o respeito aos princípios da cena a italiana e as convenções da ilusão teatral, ligada à tradição da arte dramática no teatro para atores. O teatro de bonecos homogêneo, com unidade de meios de expressão, incorpora as convenções do teatro clássico, no que diz respeito tanto ao espaço cênico, quanto ao jogo e ao tema dos espetáculos. Nas últimas décadas os artistas sentiram a necessidade de aperfeiçoá-lo, pois começam a atentar para as especificidades do boneco e do Teatro de Animação enquanto gênero dramático. Segundo este autor, o Teatro de Bonecos com características homogêneas foi praticado primordialmente até o fim da Segunda Guerra Mundial, na Europa, quando começam a surgir artistas trabalhando com um teatro de formas de expressão variadas. Mas o aparecimento de tais espetáculos não torna o teatro de bonecos homogêneo uma forma de expressão ultrapassada e de investigação esgotada. Ele continua a ter todas as condições para desenvolver seu estilo próprio, com muitos artistas trabalhando dentro desta perspectiva, pois o público ainda aceita bem a presença do boneco tradicional. Por essa razão, até os anos 1960, na Europa e Estados Unidos, ainda ocorrem inúmeras manifestações deste tipo de teatro de bonecos, coexistindo com o teatro de bonecos heterogêneo.

Nos anos 1950 e 1960, o mesmo fenômeno da existência de um teatro de bonecos homogêneo pode ser observado aqui em Santa Catarina, em duas cidades cujos

\footnotetext{
${ }^{4}$ Segundo Beltrame (2002:4) a escolha do termo Teatro de Animação se justifica por este termo dar conta de meios de expressão tão diversos e variados como máscaras, objetos, silhuetas, sombras, figurinos excêntricos, cenografias ousadas e as diversas formas do trabalho do ator-animador visível em cena. $\mathrm{O}$ termo Teatro de Bonecos é mais adequado para caracterizar formas de expressão popular, onde são utilizados bonecos construídos com as técnicas de luva, vara ou fios, com o uso do palquinho como espaço cênico e uso preponderante da palavra.

5 Ainda segundo Beltrame (2002:5) o termo ator-animador é mais adequado para identificar este artista, pois contempla a idéia de anima, alma, referindo-se muito especialmente a animar o inanimado, a dar vida ao objeto inerte, além de também expressar a idéia de diálogo entre matéria, forma e animador. Já o termo ator-bonequeiro pode conotar aquele artista que utiliza apenas o boneco enquanto o termo atormanipulador aquele que anima o boneco através do uso exclusivo das mãos.

6 BELTRAME, Valmor. Animar o Inanimado: A Formação Profissional do Ator no Teatro de Bonecos. São Paulo: ECA/USP, 2001. Tese de Doutoramento. Universidade de São Paulo

7 JURKOWSKI, Henryk. Métamorphoses. $2^{\mathrm{a}}$ ed. Charleville-Mezières: Éditions L’Entretemps, 2000.
} 
habitantes são de origem predominantemente alemã, era praticado o Kasperle, tradicional e popular Teatro de Bonecos alemão. Na cidade de Jaraguá do Sul, destacase a atuação da marionetista Margarethe Schlünzen. E na cidade de Pomerode registrase o trabalho da família Emmel. Este tipo teatro praticado nas duas cidades catarinenses possuía muitas das características de um Teatro de Bonecos homogêneo: os artistas atuavam escondidos por uma, empanada ou palquinho; os bonecos eram da técnica de luva; eram encenações nas quais o texto falado tinha sempre grande importância e um dos seus principais objetivos era provocar o riso na platéia. Este teatro, ainda que com visibilidade regional, caracteriza bem o teatro de bonecos homogêneo na forma como Jurkowsky o analisa.

Mas já a partir dos anos 1950 na Europa, os bonequeiros mais jovens não pretendendo mais restringir seu campo de criação, iniciam uma espécie de ruptura com a poética tradicional do teatro de bonecos homogêneo. Os bonequeiros buscam se profissionalizar, e o teatro de bonecos começa a se enriquecer com as contribuições do jogo do ator, das máscaras, dos acessórios e dos objetos, descobrindo assim outros meios de expressão, tendo a oportunidade de aceder a uma linguagem mais teatral, atualizada e mais poética.

O Teatro de Animação contemporâneo catarinense, assim como grande parte da produção mundial atual, se enquadra dentro do panorama do que Jurkowki chama de teatro de bonecos heterogêneo, um teatro de meios de expressão variados.

A primeira grande ruptura ocorrida em relação ao teatro de bonecos dito homogêneo, e que é considerada por muitos artistas e críticos como verdadeiro critério de modernidade do boneco, foi a introdução do ator-animador á vista, na cena. O grande esforço que era realizado anteriormente, de animar as figuras da forma mais dissimulada, mais opaca e neutra possível, foi substituído pela intromissão do ator em cena, o que deixa o espectador mais consciente de que as figuram que vê são bonecos manipulados que atuam dentro de um jogo, uma imagem da realidade. Desta forma o ator em cena no teatro de animação se constitui em um elemento epicizante ${ }^{8}$ no jogo teatral.

Jurkowsky ${ }^{9}$ declara que o cruzamento entre o teatro de bonecos e teatro de atores poderia ser o caminho para a construção de um teatro mais "teatral":

\begin{abstract}
A desmistificação da máquina teatral, os procedimentos revelados ao espectador, os inúmeros meios de expressão, de todas as origens, tudo isso tende dentro de alguns anos para um "terceiro gênero" e mostra que o teatro de bonecos clássico aparentemente teve a sua época.
\end{abstract}

(JURKOWSKY, 1966:03)

A entrada do ator em cena propicia também uma grande mudança no espaço cênico utilizado para os espetáculos. Os tradicionais palquinhos são substituídos por espaços mais amplos, que possam comportam as dimensões corporais do ator.

Os grupos catarinenses de Teatro de Animação, incluídos nesta pesquisa, podem ser considerados herdeiros do "terceiro gênero", pois trabalham na grande maioria de

\footnotetext{
${ }_{8}^{8}$ Do termo épico. Segundo Jurkowsky, (2000:123) o jogo á vista, precede a chegada de um teatro narrativo, onde o ator-animador pode ser comparado a um narrador, a um contador de histórias. Este teatro remonta a um passado muito distante e não está necessariamente ligado ao teatro épico proposto por Brecht. Ainda hoje, existem na Ásia e na Europa inúmeros contadores que ilustram suas histórias com desenho, bonecos ou figuras esculpidas. Suas palavras e suas imagens se completam umas as outras sem recorrer ao chamado distanciamento, que é a base do teatro épico de Brecht.

${ }^{9}$ JURKOWSKI, op. cit., p.84
} 
seus espetáculos com o manipulador à vista, e alguns grupos mesmo alteram a realização de espetáculos de animação com espetáculos de ator, como é o caso do Cirquinho do Revirado, da Téspis e do Teatro Sim... Porque Não?, em especial.

A companhia GATS, em seu "Patinho Feio", realiza um espetáculo de teatro de animação sem utilizar um único boneco-objeto ${ }^{10}$. O grupo cria formas animadas em cena, na presença do público, através da manipulação de partes dos corpos dos atoresanimadores e o uso de sacolas plásticas.

Dominique Houdart ${ }^{11}$ afirma que o teatro ocidental atualmente conhece uma renovação promissora devido à explosão audiovisual, que é uma marca de nossa época. No que diz respeito ao teatro de animação, este também, vez por outra, se vê contaminado com os estímulos que recebe dos meios audiovisuais.

Em sua tese de doutoramento, Felisberto Costa $^{12}$ diz que o teatro de animação, por vezes, aproxima-se do cinema, pois ambos são formas de expressão que se apóiam na imagem, e que outras vezes se aproxima do cinema de animação, pois ambos se expressam através do binômio impossível/plausível.

O espetáculo "O Incrível Ladrão de Calcinhas", de William Sieverdt, da Trip Teatro de Bonecos, com bonecos de manipulação direta, conta uma história inspirada nos filmes do gênero noir ${ }^{13}$, com direito a detetive, mulher fatal e gangster. Neste trabalho, observa-se a influência do cinema mais enquanto temática do que enquanto linguagem.

Já o espetáculo “A Caixa” da Cia. Mútua, segundo o próprio grupo, recebe a influência da linguagem dos desenhos animados. O espetáculo conta a história de um palhaço de brinquedo que é jogado no lixo. Ao se dar conta de sua situação empreende uma verdadeira odisséia através da cidade grande a procura de seu lar. Em uma das cenas, vemos o palhaço andando por uma avenida de grandes prédios. Nesta cena, o boneco do palhaço foi substituído por um duplo, mas de dimensões bem menores. Este recurso nos dá a idéia de um plano de conjunto, tipo de enquadramento emprestado da linguagem cinematográfica.

O grupo teatral Turma do Papum, no espetáculo "Gibi", ${ }^{14}$ cujo próprio título remete ao universo dos quadrinhos, apresenta em sua narrativa uma animação que representa a entrada do personagem/boneco dentro de uma estória em quadrinhos que está lendo. Há, neste caso, a utilização do próprio recurso audiovisual, uma animação apresentada em um telão, compondo o espetáculo. Através da mudança de suporte, do teatro de animação, para o cinema de animação, o diretor da peça mostra a mudança vivida pelo personagem/boneco que representa um menino, que entra no universo de seu "herói”, que é um personagem de histórias em quadrinhos. Com este procedimento, ocorre um aproveitamento extra do espaço cênico, criando novas camadas ficcionais

No Teatro de Animação catarinense encontramos uma característica presente em quase todos os grupos de artistas contemporâneos, que trabalharam com a linguagem das formas animadas: a presença de um ator-animador polivalente, capaz de executar diversas funções dentro de um grupo teatral, de construtor de bonecos a ator-animador,

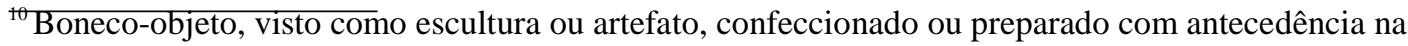
oficina de trabalho do grupo.

${ }^{11}$ HOUDART, Dominique. Manifeste pour un Théâtre de Marionnete et de Figure. Tradução: José Ronaldo Faleiro. Gennevilliers: Théâtre de Gennevilliers, 2000.

${ }^{12}$ COSTA, Felisberto Sabino da. A Poética do Ser e Não Ser: Procedimentos Dramaturgicos no teatro de Animação. São Paulo: ECA/USP, 2000. Tese de Doutoramento. Universidade de São Paulo

${ }^{13}$ Os filmes do gênero Noir, já considerado um gênero cinematográfico clássico, são estereotipados e de temática policial, que conheceram o auge de sua produção na Hollywood dos anos 1940. Os filmes eram produzidos em preto e branco, e foram batizados pelos críticos franceses com o termo noir, que em francês é o nome a cor preta, por conta de um arrojado trabalho de luz e sombra.

${ }^{14}$ Gibi: nome popular de revista em quadrinhos infanto-juvenil. 
diretor e produtor de seus espetáculos. Já em 1950, Jan Bussell escrevia, referindo-se aos bonequeiros europeus:

O bonequeiro deve ser considerado ao mesmo tempo como um artista e como um artesão. $\mathrm{O}$ artesanato é tão importante para ele como para um pintor. Mas esta é apenas uma das primeiras exigências que se tem em relação a ele. Há bonequeiros que não se elevaram jamais acima do nível de artesão e outros que têm talentos artísticos e nenhum para o artesanato. Esses dois grupos só podem alcançar o sucesso se tomam consciência dos seus limites e se engajam um pouco para compensar suas carências. (BUSSELL, 1950 apud JURKOWSKI, 2000)

No teatro de animação, a impressão de vida manisfesta-se através do movimento que o ator-animador imprime na matéria inerte. A manipulação de um boneco não deve ser uma tentativa de reproduzir o movimento humano, com exceção da marionete ${ }^{15}$; o ator-animador deve tirar proveito da especificidade do espectro de movimentos do seu próprio boneco. É importante ter em vista que as possibilidades de movimentos de um boneco são conseguidas desde o seu projeto e sua construção. Durante a criação de um espetáculo, a escolha do tipo de boneco que será utilizado está intimamente ligada às características da personagem, da organização cênica e do próprio espetáculo.

Um dos bonecos de Paulo Nazareno representa a figura mitológica do deus Pã. É um boneco de corpo inteiro, projetado para ser animado por um único ator. $\mathrm{E}$ isso só é possível, porque o construtor criou uma estrutura que liga a cabeça do boneco a cabeça do animador, deixando suas mãos livres para manipular o corpo do boneco.

Com relação às técnicas de animação, a grande maioria dos grupos catarinenses trabalha com técnicas variadas de manipulação, mesmo dentro de um mesmo espetáculo, o que indica novamente a tendência de criação de espetáculos mistos. Observa-se como técnicas predominantes o boneco de luva ${ }^{16} \mathrm{e}$ o boneco de manipulação direta $^{17}$. É bastante restrito o uso do boneco de vara e de marionetes.

Segundo Carlos Converso, ${ }^{18}$ por suas características essenciais, o boneco encontra no absurdo, no grotesco e na metáfora, sua maneira peculiar de expressar-se, pois sua imagem plástica e seus movimentos são arremedos absurdos da imagem e movimentos humanos, uma espécie de caricatura, próxima do símbolo. No espetáculo "Livres e Iguais", do grupo Teatro Sim...Porque Não?, bonecos feitos com sucatas representam as mazelas dos menos favorecidos, seres humanos rejeitados pela sociedade na qual vivem, muitas vezes considerados lixo como a sucata de que é feito o

\footnotetext{
${ }^{15}$ A marionete, ou boneco de fios, tem uma estrutura corporal que imita a estrutura corporal humana e suas articulações, o que permite que seus movimentos se aproximem dos movimentos humanos.

${ }^{16} \mathrm{O}$ boneco de luva é uma das mais populares e expressivas linguagens de animação. Anatomicamente se constitui de uma cabeça e um vestido vazio. Para ser manipulado, o ator-animador veste o boneco em sua mão, por isso essa técnica recebeu o nome de luva. Desta forma, a mão e o antebraço do seu manipulador se tornam o corpo do boneco. Neste tipo de boneco a fonte de seu movimento e sua estrutura são a mesma coisa.

${ }^{17} \mathrm{O}$ boneco de manipulação direta é uma técnica derivada do Bunraku, tradicional teatro de bonecos japonês. Esta técnica consiste em manipular a quatro ou a seis mãos um bonecos de corpo inteiro, colocando-se a mão diretamente na parte do boneco a ser manipulada, exceto a cabeça, que costuma ter uma pequena vareta de controle.

${ }^{18}$ CONVERSO, Carlos. Entrenamiento del Titiriteiro. México: Escenologia. 2000.
} 
corpo dos bonecos do espetáculo. Neste caso, a própria materialidade do boneco é fonte de expressão, refletindo a proposta temática do encenador.

A encenação deste espetáculo possibilitou, em âmbito regional, discutir a importância dos materiais com os quais são confeccionados os bonecos como elementos que interferem diretamente na dramaturgia do espetáculo. Assim, uma nova mudança se percebe no contexto catarinense: a idéia de dramaturgia já não está mais restrita ao texto, mas se expande para todos os elementos que compõe a cena. E a questão dos materiais com os quais são confeccionados os bonecos, adquire posição relevante nestas discussões.

É evidente a tendência contemporânea no Teatro de Animação da escolha de caminhos artísticos e soluções cada vez mais variados, e a diminuição da incidência do Teatros do Bonecos tradicional, o que torna difícil enquadrar estas diferentes manifestações dentro dos limites do um mesmo gênero. Isso ocorre por motivos variados, muitas vezes essas escolhas são feitas muito mais por motivos econômicos e estratégicos do que por inquietações artísticas, o que no entanto não diminui o valor dos resultados alcançados. Através da análise dos diferentes espetáculos de Teatro de Animação que estão sendo produzidos no estado de Santa Catarina, abordados no âmbito desta pesquisa, mesmo possuindo alguns traços em comum,dentre os quais se destaca o papel preponderante do sujeito criador, é difícil pensar em poéticas dominantes que norteiem o trabalho destes artistas.

\section{REFERÊNCIAS}

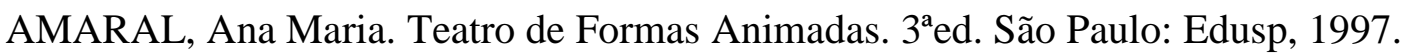
. O Ator e seus Duplos. São Paulo: Edusp, 2002.

BELTRAME, Valmor. Animar o Inanimado: A Formação Profissional do Ator no Teatro de Bonecos. São Paulo: ECA/USP, 2001. Tese de Doutoramento. Universidade de São Paulo.

CONVERSO, Carlos. Entrenamiento del Titiriteiro. México: Escenologia. 2000.

COSTA, Felisberto Sabino da. A Poética do Ser e Não Ser: Procedimentos

Dramatúrgicos do Teatro de Animação. São Paulo: ECA/USP, 2000. Tese de

Doutoramento. Universidade de São Paulo.

JURKOWSKI, Henryk. Métamorphoses: La Marionette au XX Siécle.. Tradução: Eliane Lisboa, Gisele Lamb e Kátia de Arruda. $2^{\mathrm{a}}$ ed. Charleville-Mezières: Éditions L'Entretemps, 2000.

KLEIST, Heinrich Von. Sobre o Teatro de Marionetes. Rio de Janeiro: MINC, 1952.

PAVIS, Patrice. Dicionário de Teatro. São Paulo: Perspectiva, 1999.

\section{Periódicos}

MÓIN-MÓIN. Jaraguá do Sul. SCAR/UDESC. 2005. v.1.

MÓIN-MÓIN. Jaraguá do Sul. SCAR/UDESC. 2006. v.2.

\section{Artigos}

HOUDART, Dominique. Manifeste pour un Théâtre de Marionnete et de Figure.

Tradução: José Ronaldo Faleiro. Gennevilliers: Théâtre de Gennevilliers, 2000. 